\section{The present situation, challenges, and perspectives regarding the production and utilization of effective drugs against human Chagas disease}

\author{
João Carlos Pinto Dias ${ }^{[1],[2],}$ \\ Jose Rodrigues Coura ${ }^{[2],[3]}$ and \\ Maria Aparecida Shikanai Yasuda ${ }^{[2],[4]}$
}

[1]. Centro de Pesquisas René Rachou, Fundação Oswaldo Cruz, Belo Horizonte, MG. [2]. Ex-Presidente da Sociedade Brasileira de Medicina Tropical, Brasília, DF. [3]. Laboratório de Doenças Parasitárias, Instituto Oswaldo Cruz, Fundação Oswaldo Cruz, Rio de Janeiro, RJ. [4]. Departamento de Doenças Infecciosas e Parasitárias, Faculdade de Medicina, Universidade de São Paulo, São Paulo, SP.

\section{Dear Editor,}

The first effective drugs against human Trypanosoma cruzi infection (nifurtimox, produced by Bayer, and benznidazole, produced by Roche) became available in the $1960 \mathrm{~s}^{1,2}$. Because these drugs were initially only recommended for acute cases, the international demand for their production was very low. In the subsequent 20 years, good treatment results for chronic infection in children stimulated several studies in adults with the chronic indeterminate form of the disease and even in adults in the initial stages of chronic cardiomyopathy ${ }^{3,4}$. At the end of the twentieth century, Roche transferred the production of benznidazole to LAFEPE (Laboratório Farmacêutico de Pernambuco), a Brazilian public enterprise that received its last GMP (Certificate of Good Manufacturing Practice) in $2009^{5}$. Because of the increased demand for the product and several problems with its production and distribution, the World Health Organization and the scientific community involved in research on Chagas disease have become worried in recent years about the worldwide shortage of the product, which could result in a reduced opportunity to treat millions of infected individuals $s^{6,7}$.

The present situation can be summarized as follows:

\section{News}

Since 2012, three important advances in antiparasitic treatment of Chagas disease have been made: I) the availability of benznidazole after a global shortage lasting 1.5 years; II) the announcement of new presentations of benznidazole and

\footnotetext{
Address to: Dr. João Carlos Pinto Dias. CPqRR/FIOCRUZ. Av. Augusto de Lima 1715, Barro Preto, 30190-002 Belo Horizonte, MG, Brasil.

Phone: 5531 3349-7763

e-mail: jcpdias@cpqrr.fiocruz.br

Received 31 October 2013

Accepted 4 December 2013
}

nifurtimox, and III) the updated World Health Organization (WHO) List of Essential Medicines for children ${ }^{4,7,8}$.

Benznidazole production by the Argentinean Laboratory ELEA (Laboratório Endocrínico Argentino)' ${ }^{9}$ during two international events (the Intergovernmental Initiative of the Southern Cone for Chagas Disease Elimination, Buenos Aires, August 2012, and the International Congress for Tropical Medicine and Malaria, Rio de Janeiro, September 2012), Argentinian scientists announced the initiation of benznidazole production by ELEA through a private-public partnership. This initiative was fully endorsed by scientists and several governmental health authorities. The purpose of the Argentinean production was (a) to ensure a national supply and (b) to respond to international demand. In fact, benznidazole, the first-line treatment in most countries, is increasingly prescribed for the antiparasitic treatment of chronic human Chagas disease, with an increased demand in both endemic and non-endemic countries ${ }^{6-8}$.

New presentations of benznidazole and nifurtimox ${ }^{4,5,8}$ : Two presentations of a new product, named Abarax, were registered by the Administración Nacional de Medicamentos, Alimentos y Tecnologia Médica (ANMAT) - National Administration of Drugs, Foods and Medical Devices of Argentina in January 2012: a pediatric double-scored 50-mg orally disintegrating tablet for administration to the entire pediatric population, ranging from newborns (because the tablet can be split into 4 pieces of $12.5 \mathrm{mg}$ each) to adolescents and young adults weighing $40 \mathrm{~kg}$, and a double-scored $100-\mathrm{mg}$ orally disintegrating tablet for administration to children and adults exceeding $40 \mathrm{~kg}$ in weight ${ }^{9}$.

The active pharmaceutical ingredient is manufactured by Maprimed, a company in the same international healthcare group as ELEA, in Buenos Aires. In addition, both enterprises have been nationally and internationally certified for exhibiting the good manufacturing practices required for drug formulations ${ }^{9}$.

Benznidazole 100-mg and 50-mg tablets are distributed in Latin America through the ELEA and the Pan American Health Organization (PAHO) Revolving Fund, in Spain through the Agencia Española de Medicamentos y Productos Sanitarios, and throughout the rest of the world through the ELEA and the $\mathrm{WHO}^{8,9}$.

The original price was calculated at approximately US\$60 for a bottle containing 100, 100-mg tablets and at US $\$ 40$ for a bottle containing 100,50-mg tablets. International commercialization, as in the case of the Brazilian LAFEPE, will depend on national registrations in each country or on international agreement terms involving international health agencies such as the PAHO and the $\mathrm{WHO}^{5,7-10}$.

After the first year of use, the quality of Abarax has proven satisfactory with respect to adverse events and its availability in the country according to local scientists, regulatory agencies, and general physicians involved in the official project Plan de Gestión de Riesgo, led by the Argentinian Ministry of Health ${ }^{9}$.

Since 2008, the only enterprise producing the drug has been LAFEPE. Several problems and difficulties were encountered, 
including higher scale production; acquisition of the active ingredient that was no longer being provided by the former producer (Roche $\left.{ }^{\circledR}\right)$; delivery of the product to other countries; and high final prices after distribution in Latin America, the United States, and Europe by Masters Limited, an international private trade enterprise, for instance reaching $€ 105$ in Spain (a 9-fold increase above the base price). Finally, a longstanding problem involves the lack of official certification of good manufacturing practices by LAFEPE since February $2010^{7,10}$.

The updated World Health Organization List of Essential Medicines for children: in April 2013, the $19^{\text {th }}$ Expert Committee on the Selection and Use of Essential Medicines of WHO discussed and approved the addition of two new benznidazole presentations in the list of essential medicines for children. Unlike nifurtimox, which included adult and pediatric presentations of 120 and $30 \mathrm{mg}$, respectively, there was a lack of benznidazole presentations for people weighing less than $40 \mathrm{~kg}$. The main advantage of the $12.5-\mathrm{mg}$ tablet is that it can be used to treat newborns to 2-year-old children, facilitating proper dosing without having to break and handle pieces of larger tablets. Additionally, the main advantage of the 50-mg tablet is that it can be used to treat the entire pediatric population, including adolescents and young adults s., $^{3,8,9}$.

\section{Future new drugs and drug combinations}

In contrast, the expectations of scientists and public health specialists for other new drugs to be made available in a short time period were not met, mainly due to the apparent lack of success of posaconazole treatment as a monotherapy in a recent clinical trial performed in the Catalan Institute of Health and presented at the International Congress for Tropical Medicine and Malaria in 2012. Unfortunately, the results of future clinical assays with drug combinations not already tested will take time to obtain ${ }^{1-3,7}$.

It also seems evident that a newer, more effective drug than benznidazole or nifurtimox will not be available in the near term (i.e., for 5 years or more).

Nevertheless, scientists stress that research on new drugs and better protocols for the specific treatment of Chagas disease (including combination therapies) should be a priority for researchers and agencies involved in Trypanosomiasis ${ }^{1,3}$. This strategy is the same as that adopted by the WHO Strategic and Technical Advisory Group for Neglected Tropical Diseases at its target-setting meeting in April 2011.

\section{Production of quality-assured drugs}

Drugs for neglected tropical diseases are key for control and elimination. In addition to their potential to treat and cure patients, secondary and tertiary prevention with benznidazole and nifurtimox should be used to promote healthcare and strengthen surveillance systems (with information on patients and transmission routes). The treatment of patients with these drugs should be monitored with pharmacovigilance, and studies should be designed to improve the present dosages and protocols.

Indeed, pharmacovigilance is a critical and still neglected area that demands urgent attention by manufacturers and relevant official health departments ${ }^{7}$.
Another area requiring urgent attention is the need for in vivo bioequivalence and comparative studies for both the LAFEPE and ELEA to assess new presentations and geographical differences in the therapeutic response to update present management protocols because the original Roche product is no longer available $\mathrm{e}^{7,8}$.

\section{Challenges and opportunities}

Furthermore, there is a need to promote case detection, especially due to the global shortage of benznidazole and the consequent decrease in diagnosis and treatment worldwide. In 2013, several endemic and non-endemic countries began to consider whether to expand the range of specific treatment for human Chagas disease to chronic-phase cases, especially those with indeterminate forms $\mathrm{s}^{1-3,8}$.

Moreover, the WHO and several scientific institutions are advising that the international demand for the product can be met in the near future if the final results of the Benefit Project suggest a concrete clinical benefit to affected individuals classified in the first two levels of chronic cardiomyopathy. They understand that this demand could also increase given the increasing number of diagnoses of Chagas infection through blood-bank screening worldwide and by the regional health systems in Latin America ${ }^{6,7}$.

In parallel, crucial questions concerning drug costs and drug quality must be responsibly addressed by governments, producers, and health authorities. Especially relevant is the role of the national regulatory agencies, which have full autonomy and independence, to ensure the best quality drugs. There is also a concern that such drugs may cost more in the future, which could considerably limit their use in the poorest areas and populations that are characterized by endemic Chagas disease. It would be ideal, and politically more astute, if Brazil, currently the main producer of the drug and the leader in initiatives and research on Chagas disease, were to make the decision to guarantee the current price or to make the drug available free of charge as a token of solidarity with the impoverished, infected people throughout the world.

Scientists and public health specialists wish to highlight the importance of ensuring that the global distribution of benznidazole is secure, directly involving each national government and respective agencies for product registration. An alternative could be drug donations to the $\mathrm{WHO}$ and its regional offices for delivery to consumer countries, as is done for other Negleted Tropical Diseases (NTDs). This solution would avoid the need for the costly registration of the drug in each country and the need to renew registration every five years.

Finally, at the contextual and operative levels, recent WHO and PAHO workshops have recognized that better and more extensive treatment of Chagas disease urgently requires the availability of diagnostic tools and a sufficient number of skilled doctors, especially at the primary health-care level, and the involvement of regional and national reference centers ${ }^{2,38}$.

\section{Conclusions and recommendations}

The WHO considers the regular administration of a specific treatment against several neglected diseases to 
be not only a mandatory task for improving public health but also an excellent epidemiological tool for monitoring such diseases and evaluating their control and elimination.

In the case of benznidazole, the different countries must be provided with realistic data concerning their annual demand for the product and the regularity of its production. In parallel, each country must be provided with adequate conditions to maintain control of the stocks, product evaluation, and pharmacovigilance concerning these drugs.

The sustained production of quality-assured medicines against Chagas disease is needed for at least two or three decades, given the current epidemiological scenarios of its incidence and transmission control.

The donation of quality-assured medicines, especially for congenital and pediatric cases, is timely given the necessity of promoting one of the most cost-effective interventions in the control of Chagas disease.

\section{CONFLICT OF INTEREST}

The authors declare that there is no conflict of interest.

\section{REFERENCES}

1. Coura JR, Castro SL. A critical review on Chagas disease chemotherapy. Mem Inst Oswaldo Cruz 2002; 97:3-24.

2. Dias JCP, Macedo VO. Doença de Chagas. In: Coura JR, editor. Dinâmica das doenças infecciosas e parasitárias. Rio de Janeiro: Guanabara Koogan; 2005. p. 557-594.
3. Andrade JP, Marin-Neto JA, Paola AA, Vilas-Boas F, Oliveira GM, Bacal F, et al. Diretriz Latino Americana para o Diagnóstico e Tratamento da Cardiopatia Chagásica. (Latin American guidelines for the diagnosis and treatment of Chagas cardiomyopathy). Arq Bras Cardiol 2011; 97 (supl II):1-47.

4. Ministério da Saúde. Consenso Brasileiro em Doença de Chagas. Rev Soc Bras Med Trop 2005; 38 (supl III):7-29.

5. Medeiros FPM. Current situation and new perspectives for the treatment of Chagas disease. Prospects for production and distribution of benznidazole. Rev Soc Bras Med Trop 2009; 42 (supl II):79.

6. Navarro M, Norman FF, Pérez-Molina JA, López-Vélez R. Benznidazole shortage makes Chagas disease a neglected tropical disease in developed countries: data from Spain. Am J Trop Med Hyg 2012; 87:489-490.

7. Brazilian Society on Tropical Medicine. O impacto mundial da interrupção da produção do benznidazol pelo Brasil: como contornar a crise de desabastecimento? Official motion from the $27^{\text {th }}$ international meeting on Chagas Disease applied research (Uberaba, Brazil) addressed to the Brazilian Ministry of Health and the Scientific Community; 2011. Available at: http://blogdeparasitologia.files.wordpress.com/2011/11/ mocao_da_xxvii_reuniao_anual_de_pesquisa_aplicada_em_doenca_de_ chagas_20111.pdf

8. World Health Organization. Pan American Health Organization. INCOSUR. Final report and conclusions of the XIX Intergovernmental Meeting. Santiago de Chie, October 8: Mimeog; 2013.

9. Sosa-Estani S. La producción de benznidazol en Argentina. Oficial report to the XIX Reunión de la Comisión Intergubernamental (CI) de la Iniciativa Subregional Cono Sur de Eliminación de Triatoma infestans y Interrupción de la Transmisión Transfusional de la Tripanosomiasis Americana. Termas de Rio Hondo, Argentina, Octubre 8; 2013.

10. Rezende KS. Producción Brasileña de Medicamentos y Ingrediente Activo de Benznidazol. Official report to the XIX Reunión de la Comisión Intergubernamental (CI) de la Iniciativa Subregional Cono Sur de Eliminación de Triatoma infestans y Interrupción de la Transmisión Transfusional de la Tripanosomiasis Americana. Termas de Rio Hondo, Argentina, Octubre 8; 2013. 